\title{
Hydraulic Design of Thermally Coupled Columns and a DWC for NGL Fractionation Plants
}

\author{
I. Dejanović, a, $^{, k}$ I. J. Halvorsen, ${ }^{b}$ H. Jansen, ${ }^{c}$ and Ž. Olujić ${ }^{d}$ \\ ${ }^{a}$ University of Zagreb, Faculty of Chemical Engineering and Technology, \\ Department of Reaction Engineering and Catalysis, Savska cesta 16, \\ 10000 Zagreb, Croatia \\ bSINTEF Digital, Mathematics and Cybernetics, \\ PO Box 4760, Trondheim, Norway \\ 'Julius Montz GmbH, Hofstraße 82, Hilden, Germany \\ ${ }^{\mathrm{d}}$ Retired, The Hague, The Netherlands
}

doi: 10.15255/CABEQ.2018.1418

Received: June 29, 2018

Accepted: December 21, 2018

\begin{abstract}
Combining a conventional demethanizer with thermally coupled deethanizer and propane-butane recovery columns or a three-product dividing wall column (DWC) provides a realistic opportunity for natural gas liquids (NGL) fractionation complexes as encountered in floating, as well as on-land natural gas liquefaction plants, to minimize energy requirements and reduce carbon dioxide emissions accordingly, in a cost-effective way. The present paper addresses and discusses hydraulic design aspects of these two thermal coupling arrangements, including the choice of the most appropriate column internals that largely depends on important design, construction, and operating considerations that differ for floating and on-land plants.
\end{abstract}

Keywords:

dividing wall column, natural gas processing, NGL fractionation, thermal coupling

\section{Introduction}

In order to meet current carbon dioxide emission reduction challenges, natural gas processing and refining industries have to find ways to minimize energy requirements of distillation operations. As indicated in a preliminary feasibility study ${ }^{1}$ and demonstrated by detailed simulation in a preceding effort $^{2}$, this could be achieved cost-effectively in a floating natural gas liquids (NGL) fractionation plant by combining a conventional demethanizer column with either a thermally coupled direct sequence of deethanizer and propane-butane $(\mathrm{C} 3+\mathrm{C} 4)$ recovery columns, or a dividing wall column (DWC).

Figs. 1 and 2 show simplified flowsheets of externally and internally thermally coupled arrangements considered appropriate ${ }^{2}$ for this demanding application, both preceded by a conventional demethanizer. The former consists of a thermally coupled deethanizer and $(\mathrm{C} 3+\mathrm{C} 4)$ recovery columns from a conventional direct three-column sequence. The fourth product stream in this arrangement is a $\mathrm{C} 5+$ fraction, leaving the bottom of the $(\mathrm{C} 3+\mathrm{C} 4)$ column. This is typical for floating facilities, while

"Corresponding author: E-mail: ideja $@$ fkit.hr, phone: +385 1 4597134, fax: +38514597133 on-land NGL fractionation plants also include columns for separation of propanes and butanes as well as a de-isobutanizer, providing opportunities for different approaches to heat coupling, including employment of DWCs where appropriate ${ }^{3,4}$.

As shown in Fig. 2, in the simple separation case, the deethanizer and $(\mathrm{C} 3+\mathrm{C} 4)$ columns are integrated into a DWC, with the cold rectification section of the deethanizer (prefractionator) column placed above the hotter main column. In such a column shell extending arrangement, the temperature difference over the dividing wall in the partitioned section of the column is not large enough to induce performance-deteriorating effects 5 .

On the processing side, with the same refrigeration demand, the heat-coupled arrangements require $10 \%$ less energy for the same separation task, compared to a conventional direct sequence ${ }^{2}$. This is a much lower saving than usual in the case of three-product separations utilising DWC and external thermal coupling technologies. However, such a saving in heating energy, though not attractive enough at first sight, translates into an equivalent carbon dioxide emissions reduction that may appear highly appealing and move the natural gas processing industry toward properly considering implementation of heat coupling in their offshore and onshore plants. 


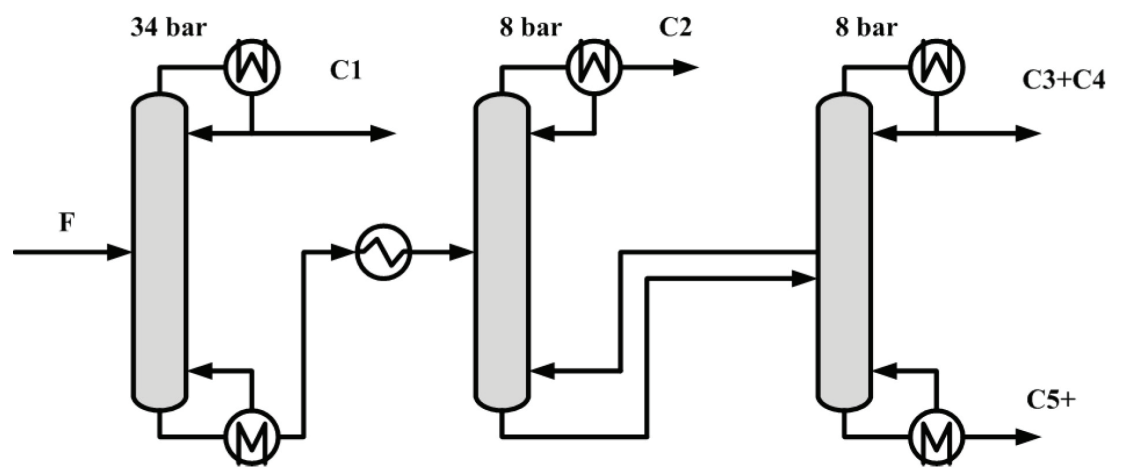

Fig. 1 - Conventional demethanizer \& thermally coupled direct sequence (TCDS)

Nevertheless, from the energy saving potential standpoint, even in this poor application (a feed mixture with extremely wide boiling range, unfavourable compositions and relative volatilities of key components), it is possible to further reduce the heating demand, i.e., reboiler duty, but this would require adopting a heat coupling arrangement that would be more complex in both design and control ${ }^{1}$.

Although it is perfectly clear that the proposed TCDS and DWC configurations allow significant reduction in capital and operating costs as well as carbon dioxide footprint compared to conventional column sequences, the natural gas processing industries still appear to be hesitant in making the next, most decisive, physical implementation step in that direction. Anticipating that the need for more solid quantitative information related to design and construction of thermally coupled single and two-shell columns as employed in proposed configurations may be the reason for the reluctance in this respect, the present paper aims at closing this gap.

The main challenge for floating applications stems from the fact that required separations are carried out at high to moderate pressures, which implies employment of tray columns. Trays, being prone to detrimental liquid and vapour maldistribution effects induced by motion of the floating facility, are generally avoided in offshore applications, where random and structured packings, being less sensitive in this respect, are considered an appropriate choice ${ }^{6-8}$. Here, a compact design (less weight and plot area), i.e., a DWC, though taller than any two columns in a thermally coupled direct sequence (TCDS) arrangement, may be a preferred option. However, in on-land applications with often much higher capacity applications, the latter allows use of common, well-proven tray distillation columns. In addition, on a floating facility, the reduced shell height makes a column less exposed to motion-induced efficiency loss. A detailed account of specific features of low- and high-pressure distillation and their influence on equipment choice can be found elsewhere?.

Regarding the internal transport and distribution of vapour, a DWC configuration is straightforward in this respect, and the desired vapour split is arranged by balancing appropriately the pressure drop in the partitioned sections of the column ${ }^{10}$. In TCDS arrangement (see Fig. 1), the required amount of vapour from $(\mathrm{C} 3+\mathrm{C} 4)$ column needs to be extracted somewhere around the feed stage and transported to the deethanizer column via a rather long line including at least two bends. This transport line is a source of additional pressure drop that needs to be accounted for appropriately to ensure the desired vapour split. The total amount of pressure drop involved in both configurations will depend on the internals chosen.

The aim of this study was to provide a clear picture in this respect, and a consistent basis for a quantitative comparison of alternative packing and tray-based designs of TCDS and DWC configura-

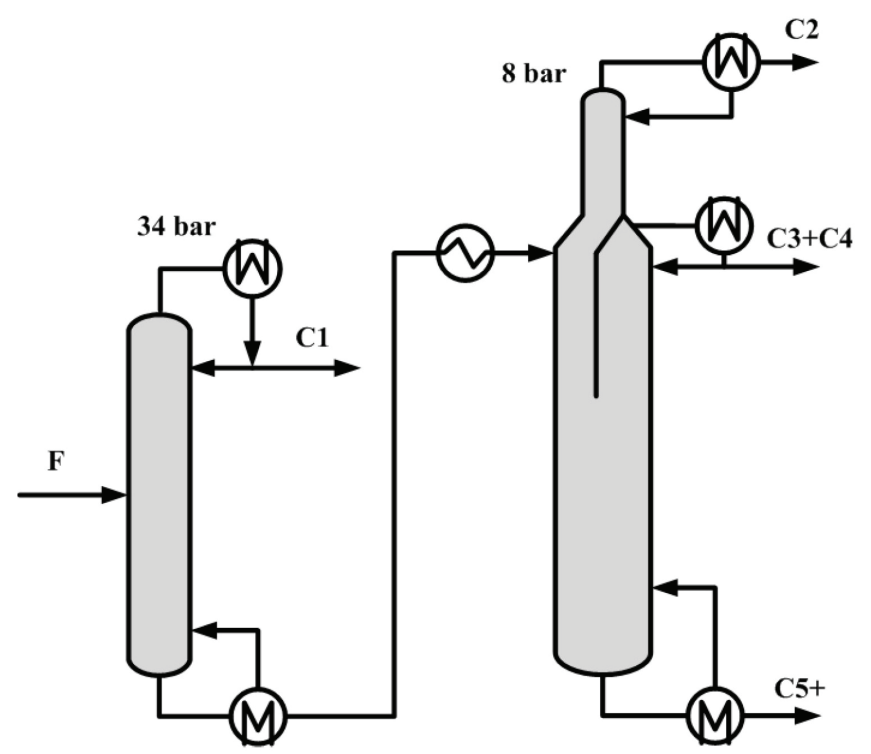

Fig. 2 - Conventional demethanizer \& dividing wall column $(D W C)$ 
tions. These are explored using the column sizing methodology developed and validated in earlier joint efforts ${ }^{10-12}$, which is extended here to allow hydraulic design of two-shell heat coupling options, taking a simple floating fractionation plant situation as the base case.

\section{Design case}

The floating facility NGL fractionation case from previous studies ${ }^{1,2}$ was considered for exploitation of a marginal field, and the feed flow rate, i.e., processing capacity $\left(7 \mathrm{t} \mathrm{h}^{-1}\right)$ was rather small. In order to arrive at column dimensions that would allow hydraulic design and comparison of packed and trayed columns for the same task, the feed rate for the present base case was increased by factor 10 , to around $70 \mathrm{t} \mathrm{h}^{-1}$. Table 1 shows specified feed composition and product composition as obtained by simulation of the conventional sequence. Product compositions were in accordance with required specifications, as follows:

- C1: > 98 mol. \% methane

- C2: $>90$ mol. \% ethane, $<2$ mol. \% propane

- C3+C4: sum of C5 compounds (2-2-Dimethylpropane, $i$-Pentane and $n$-Pentane) must be less than $0.5 \mathrm{~mol} . \%$.

In a conventional three-column direct sequence, the demethanizer operates at a top pressure of 34 bar, deethanizer at 17 bar, and the $(\mathrm{C} 3+\mathrm{C} 4)$ column at $7 \mathrm{bar}^{2}$. In a thermally coupled direct sequence, (TCDS) case, the deethanizer operates at a much lower pressure, around 8 bar at the top, similar to the $(\mathrm{C} 3+\mathrm{C} 4)$ column. Absolute, top-of-the-column pressures mentioned here are given as rounded numbers. These correspond to the condenser pressure, and in all simulations, a 0.3 bar pressure drop has been assumed between reflux drum and the top of the column. In other words, in all simulations, the operating pressure at the top of the column is 0.3 bar higher than the given value, while the pressure at the bottom of the columns depends on the pressure drop, which, in turn, depends on the internals chosen.

Note that the pressure drop of trayed columns is much higher than that of packed columns; however, in these high-pressure distillation cases, the amount of pressure drop involved is relatively small to exhibit any significant influence on the phase equilibrium and tray or packing efficiency. Therefore, there was no need to make additional iterations to refine stage requirement calculations for relatively small changes in pressure drop experienced during column sizing. A schematic representation of material and energy balance of TCDS arrangement, including molar flow rates of internal liquid and vapour streams that served as basis for
Table 1 -Feed and product specifications for NGL fractionation in a $L N G$ plant

\begin{tabular}{|c|c|c|c|c|c|}
\hline Stream/Column Name & Feed & $\mathrm{C} 1$ & $\mathrm{C} 2$ & $\mathrm{C} 3+\mathrm{C} 4$ & $\mathrm{C} 5+$ \\
\hline Temperature, ${ }^{\circ} \mathrm{C}$ & 54.0 & -91.7 & -38.9 & 33.6 & 154.0 \\
\hline Pressure, bar & 34 & 34 & 8 & 8 & - \\
\hline $\begin{array}{l}\text { Vapour mole } \\
\text { fraction, - }\end{array}$ & 0.09 & 1.00 & 1.00 & 0.00 & 0.00 \\
\hline $\begin{array}{l}\text { Molar flow rate, } \\
\mathrm{kmol} \mathrm{h}^{-1}\end{array}$ & 1085 & 174 & 92 & 299 & 520 \\
\hline Mass flow rate, $\mathrm{kg} \mathrm{h}^{-1}$ & 69510 & 2820 & 2708 & 15596 & 48386 \\
\hline \multicolumn{6}{|c|}{ Composition, mol \% } \\
\hline Methane & 16.38 & 98.97 & 5.80 & 0.00 & 0.00 \\
\hline Ethane & 8.19 & 1.02 & 92.82 & 0.58 & 0.00 \\
\hline Propane & 11.73 & 0.00 & 1.38 & 42.09 & 0.00 \\
\hline$i$-Butane & 6.08 & 0.00 & 0.00 & 22.04 & 0.00 \\
\hline$n$-Butane & 9.81 & 0.00 & 0.00 & 34.87 & 0.40 \\
\hline 2-2-Dimethylpropane & 0.46 & 0.00 & 0.00 & 0.39 & 0.74 \\
\hline$i$-Pentane & 6.45 & 0.00 & 0.00 & 0.02 & 13.46 \\
\hline$n$-Pentane & 4.76 & 0.00 & 0.00 & 0.00 & 9.93 \\
\hline$n$-Hexane & 6.00 & 0.00 & 0.00 & 0.00 & 12.54 \\
\hline Benzene & 0.62 & 0.00 & 0.00 & 0.00 & 1.29 \\
\hline$n$-Heptane & 20.07 & 0.00 & 0.00 & 0.00 & 41.90 \\
\hline Toluene & 0.59 & 0.00 & 0.00 & 0.00 & 1.24 \\
\hline Heavies & 8.86 & 0.00 & 0.00 & 0.00 & 18.50 \\
\hline
\end{tabular}

dimensioning of TCDS and DWC configurations using packings and trays, can be found in our previous paper².

For packed columns, the well-established Montz-pak 350MN, proven in numerous DWC applications, was chosen. A rather conservative value for packing efficiency $(\mathrm{HETP}=0.45 \mathrm{~m})$ was chosen to anticipate for certain loss of efficiency due to operation under high-pressure conditions, i.e., at rather high specific liquid loads. However, to ensure proper functioning of structured packing in these applications, the bed height was limited to $6 \mathrm{~m}$ and column diameters were chosen to comply with maximum specific liquid load criterion set at $30 \mathrm{~m}^{3} \mathrm{~m}^{-2} \mathrm{~h}^{-1}$ at critical locations. For this reason, the vapour loads in nearly all the cases are well below $50 \%$ of the flood. This implies a low-pressure drop operation and is also beneficial for efficiency, which, as observed in large scale total reflux test carried out with Montz-pak B1-350MN at Bayer TS in Leverkusen, Germany, and Fractionation Research Inc. (FRI), at Stillwater, OK, USA, tends to improve with decreasing vapour load ${ }^{13,14}$. 

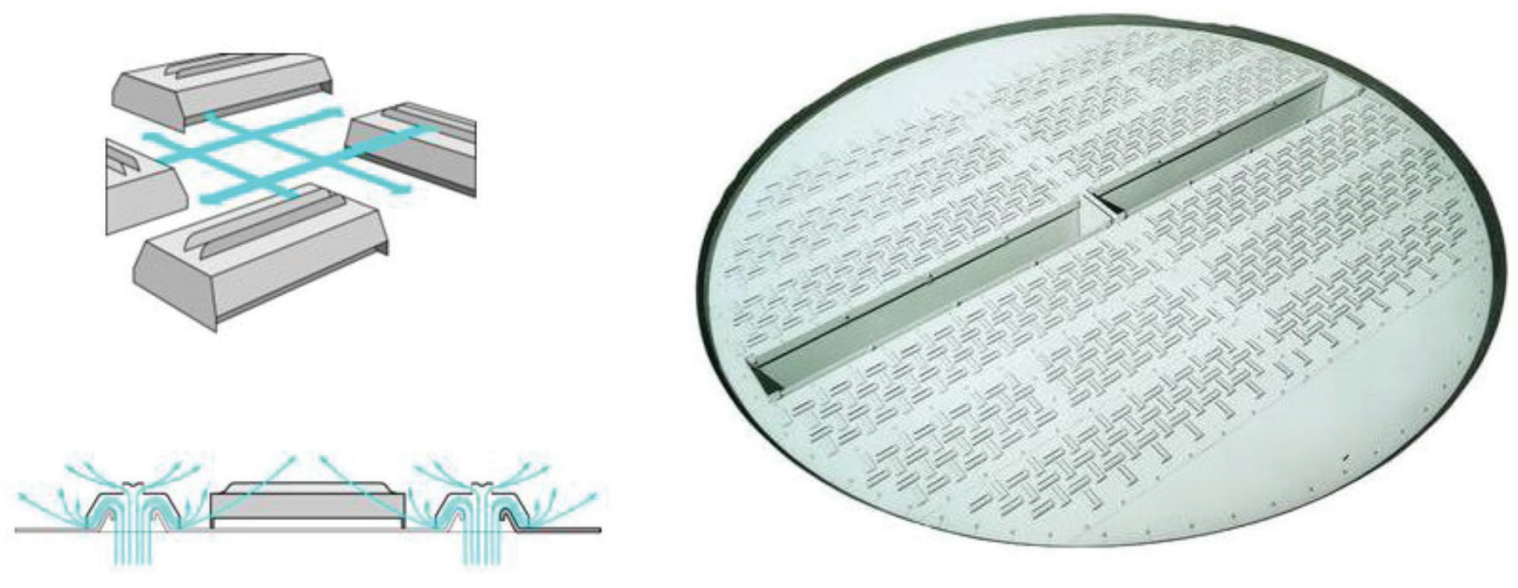

Fig. 3 -Photograph of a two-pass KSG tray with inserted sketches indicating vapour flow patterns

Upon adopting above mentioned bed height and specific liquid load limitations, dimensioning of conventional packed columns as employed in TCDS arrangement is straightforward. Arranging a proper internal layout of a DWC is quite demanding because it implies longitudinal and lateral positioning of the partition wall. The former is fixed by given stage distribution requirement, while the latter requires a trial-and-error approach to arrange properly the amount of pressure drop by design that will ensure establishing the required ratios of molar flow rates of vapour and liquid in partitioned sections during operation. A schematic illustration of the dimensioning procedure for a three-product DWC, including two iteration loops, can be found in a paper by Dejanović et $a l .{ }^{10}$, together with pressure drop estimation methods for structured packings, and typical state of the art internals, i.e., narrow trough liquid distributors, chevron (vane)-type and chimney-type liquid collectors. In this reference, all working equations are described in detail, including analytical expressions relating the lateral position of partition wall with cross-sectional area of partitioned sections. These are translated into diameters of an equivalent cylindrical column that are used, in conjunction with local vapour and liquid loads, to check the upper limit, which, in this particular case, is not a maximum vapour load or a specific pressure drop, but given value of the maximum allowable specific liquid load.

Tray columns in this design exercise are equipped with Montz Cross Flow Trays - so called KSG trays, which is the first-ever commercial fixed-valve tray introduced by Montz in the early 1970s. This high capacity tray was evaluated and performed accordingly in a FRI test ${ }^{15}$. A photograph of a two-pass KSG tray is shown in Fig. 3, and inserted sketches indicate the working principle (www.montz.de). However, being much more expensive, KSG could not compete with traditional and novel valve trays and modern fixed valve trays, but continues to be used as a capacity-increasing option in a number of well-established applications. Certainly, it could be considered appropriate for applications proposed in this study. However, for the purposes of this study, some assumptions have been made regarding tray column efficiency. These are on the conservative side: $50 \%$ for demethanizer, 60 $\%$ for deethanizer, and $80 \%$ for $(\mathrm{C} 3+\mathrm{C} 4)$ recovery column ${ }^{16}$. The tray spacing in all cases is $0.6 \mathrm{~m}$. Regretably, there is no method available in the public domain that could allow preliminary dimensioning of distillation columns equipped with state of the art high capacity trays with appropriate accuracy. To ensure reasonable accuracy in this respect, for purposes of the present study, the pressure drop of chosen KSG trays was estimated using a Montz inhouse (proprietary) model.

Tangent-to-tangent shell height has been determined summing up all relevant factors, which differ for packed and tray columns to a certain extent. To be consistent, for both packed and trayed columns, the height above the top stage and below the lowest stage was taken to be $1.5 \mathrm{~m}$ and $3.0 \mathrm{~m}$, respectively. Since in all cases considered there was a large difference in the diameter of rectification and stripping section of conventional columns, the height of conical diameter reduction part was taken to be $2.0 \mathrm{~m}$ for all cases. The exception in this respect was the DWC, where the difference in diameters of main body and upper section (rectification section of the prefractionator, i.e., deethanizer column) was much larger, and therefore, the length of conical part was increased to $2.5 \mathrm{~m}$. In packed columns, the spacing required for installation of liquid collector and distributor between two beds was taken to be $2.0 \mathrm{~m}$ in all cases. For cost estimation, which is out of the scope of this study, the shell height should in all cases be extended to include the height $(2.0 \mathrm{~m}-2.5$ m) of the skirt. 


\section{Column sizing results and discussion}

The top pressures and stage requirements as obtained by detailed simulations for conventional demethanizer combined with thermally coupled deethanizer and $(\mathrm{C} 3+\mathrm{C} 4)$ columns taking into account the pressure drop are summarized in Table 2, where indices $r$ and $s$ denote rectification and stripping section, respectively. Since TCDS and DWC configurations are thermodynamically equivalent, given stage count is valid for both configurations.

Table 3 shows diameters and tangent-to-tangent heights of shells of conventional demethanizer, and deethanizer and $(\mathrm{C} 3+\mathrm{C} 4)$ columns in thermally coupled direct sequence (TCDS) and their counterparts integrated into a DWC arrangement, dimensioned as packed and tray columns. To ease comparison, under "DWC", the prefractionator and main column are shown separately, similar to TCDS arrangement. The former is in fact the deethanizer column from TCDS, while the latter is equivalent to $(\mathrm{C} 3+\mathrm{C} 4)$ column in the TCDS arrangement.

Table 2 -Operating pressures at the top of the columns and corresponding stage requirements for conventional three-column direct sequence, thermally coupled direct sequence (TCDS) and DWC configuration

\begin{tabular}{l|c|c|c}
\hline \multicolumn{1}{c|}{ Columns } & $\mathrm{C} 1$ & $\mathrm{C} 2$ & $(\mathrm{C} 3+\mathrm{C} 4)$ \\
\hline$p_{\text {top }}($ bar $)$ & 34 & 8 & 8 \\
$N_{\mathrm{r}}(-)$ & 9 & 4 & 19 \\
$N_{\mathrm{s}}(-)$ & 10 & 13 & 35 \\
$N(-)$ & 19 & 17 & 54 \\
\hline
\end{tabular}

Table 3 -Shell diameters and heights of conventional demethanizer and columns in a thermally coupled direct sequence (TCDS) and DWC configuration, equipped with trays and structured packing

\begin{tabular}{l|c|c|c|c|c}
\hline \multicolumn{7}{l|}{} & \multicolumn{2}{c|}{ TCDS } & \multicolumn{2}{c}{ DWC } \\
\hline Columns & $\mathrm{C} 1$ & $\mathrm{C} 2$ & $(\mathrm{C} 3+\mathrm{C} 4)$ & $\mathrm{C} 2$ & $(\mathrm{C} 3+\mathrm{C} 4)$ \\
\hline \multicolumn{5}{c}{ Equipped with trays } \\
\hline$d_{\mathrm{r}}(\mathrm{m})$ & 1.0 & 0.9 & 2.1 & 0.8 & 2.1 \\
$d_{\mathrm{s}}(\mathrm{m})$ & 2.5 & 2.0 & 2.9 & 2.0 & 2.9 \\
$N_{\text {act }}(-)$ & 40 & 30 & 69 & 30 & 69 \\
$h_{\mathrm{tt}}(\mathrm{m})$ & 29.3 & 23.3 & 46.1 & \multicolumn{2}{c}{51.4} \\
\hline
\end{tabular}

\begin{tabular}{lccccc}
\hline \multicolumn{5}{c}{ Equipped with packings } \\
\hline$d_{\mathrm{r}}(\mathrm{m})$ & 1.20 & 0.65 & 1.42 & 0.65 & 1.42 \\
$d_{\mathrm{s}}(\mathrm{m})$ & 3.30 & 2.87 & 3.20 & 2.87 & 3.20 \\
$h_{\mathrm{tt}}(\mathrm{m})$ & 17.3 & 15.5 & 39.0 & \multicolumn{2}{c}{41.6} \\
\hline
\end{tabular}

Due to a relatively smaller amount of light components in the feed mixture, the diameters of rectification sections of conventional demethanizer and deethanizer and $(\mathrm{C} 3+\mathrm{C} 4)$ columns from thermally coupled arrangement are much smaller than diameters of corresponding stripping sections. Interestingly, the diameters of packed columns are generally larger, because, these are, as mentioned before, based on given maximum specific liquid load, and operate at vapour loads well below common design values $(70 \%$ of the flood). The tray columns have been dimensioned close to $70 \%$ of the flood as design point.

In present case, it is assumed that both packings and trays will operate in a DWC with the same efficiency as in conventional columns. A detailed drawing of the packed DWC with all relevant dimensions is shown in Fig. 4. The short small-diameter section at the top of the column accommodates the rectification section of the prefractionator, i.e., deethanizer. Note that in a DWC arrangement, the partition wall separates the stripping section of the deethanizer from the rectification section of the $(\mathrm{C} 3+\mathrm{C} 4)$ column, and in the case of packed DWC, the partition wall is in off-centre position, i.e., shifted towards the products' side. In this particular case, the cross-sectional area on prefractionator side is made much larger to reduce the specific liquid load accordingly. This, however, has no adverse effect on hydraulic design on main column side, because in this much narrower section, the operating vapour load is still below $50 \%$ of the flood.

In the DWC equipped with trays, the cross-sectional areas on two sides of the partition wall are nearly equal. Due to much larger liquid load, twopass trays are considered an appropriate choice on prefractionator side, while on main column side the single-pass trays with an adequate number of caps will suffice (see sketch shown in Fig. 5).

As indicated in Table 3, the shell heights of all trayed columns are considerably larger than those of their packed counterparts, and in the case of two DWCs the difference in shell height is nearly $10 \mathrm{~m}$. Even if we would take a more conservative packing efficiency, i.e., an HETP of $0.5 \mathrm{~m}$, the height advantage would still be on packed column's side.

In conjunction with given vapour loads, the installed packings and related auxiliary equipment, such as liquid collectors and distributors, as well as trays, generate a pressure drop that needs to be accounted for properly in order to allow pressure-drop balancing necessary to ensure required vapour split. This needs to be arranged by design, however, most importantly, in both cases, a TCDS or DWC, if needed, the condensing duty of deethanizer column can be manipulated to make necessary adjustments and maintain the required vapour split. 


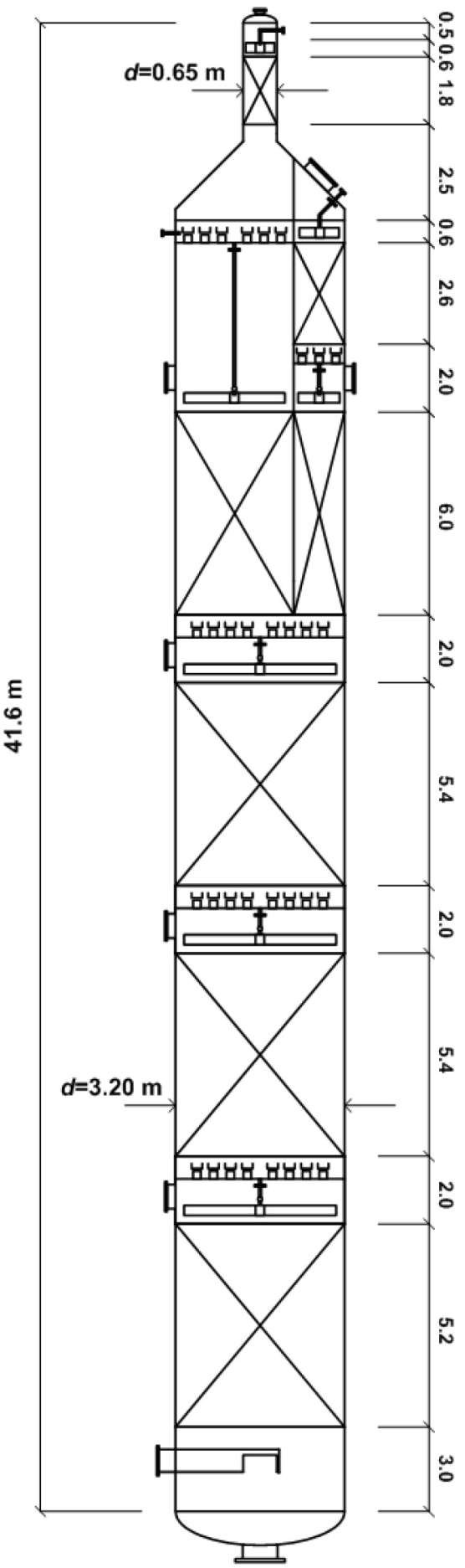

Fig. 4 - Detailed drawing of a packed DWC for NGL fractionation plant considered in this study

In case of a DWC equipped with packings, balancing the pressure drop during design is relatively easy, because the free area of liquid collectors is manipulated accordingly to adjust and equalize pressure drop on two sides of partition wall, taking into account the contribution of static pressure of vapour column on prefractionator column side, due to a significant difference in elevations of the pre-

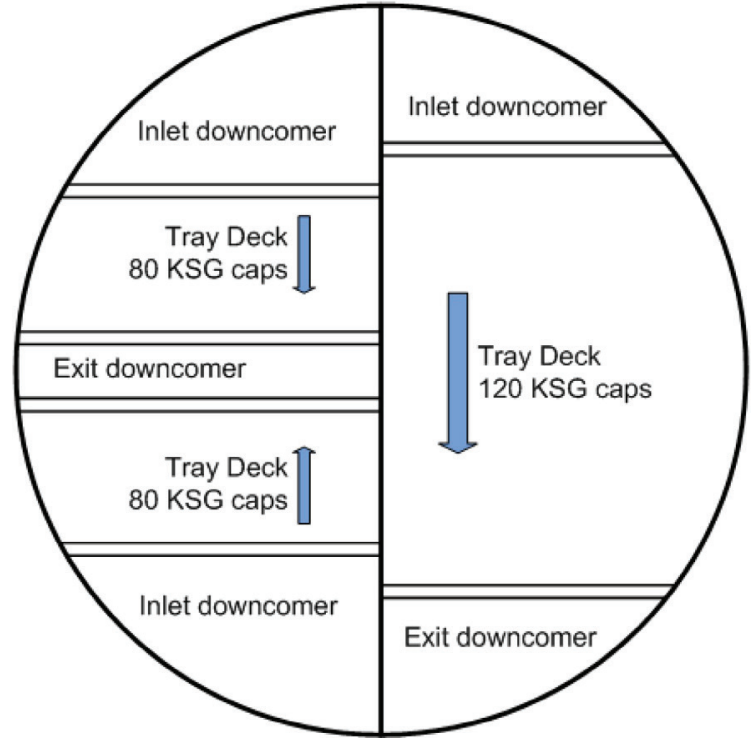

Fig. 5 - Layout of partitioned section of trayed DWC, with two-pass KSG trays on prefractionator side and single-pass trays on main column side (Full arrows indicate direction of liquid flow)

fractionator column top and the main column top. This is important to consider, because at the operating pressure as employed in this case (around 8 bar), vapour density is rather high $\left(\sim 14.6 \mathrm{~kg} \mathrm{~m}^{-3}\right)$, making the static pressure of vapour column significant and contributing appreciably in this particular case to the pressure drop on prefractionator column side, to the extent depending on the type of installed internals.

The main results of detailed pressure-drop calculations for packed DWC performed using Excel, are given in Table 4 separately for packed beds, liquid distributors, and liquid collectors. Packed bed heights, cross-sectional areas and diameters are given per section of the column. For narrow trough liquid distributors, which are all designed with free area of $40 \%$, the positions and corresponding vapour loads (F-factors) are given. For liquid collectors also the specific liquid load as well as the corresponding free area is given.

For packed DWC, the height of vapour column is $\sim 5.7 \mathrm{~m}$, which generates a static pressure of $\sim$ 8.2 mbar. With this, as shown in Table 4, the pressure drop on prefractionator side is larger, but this can be compensated by reducing the free area of two liquid collectors on main column side to about $10 \%$. This is illustrated at the bottom part of Table 4 , which shows the outcome of pressure-drop equalization calculations for two sections separated by partition wall. With this, the pressure drop is balanced and both partitioned sections can be operated at the same top pressure, 8.3 bar in this case.

For the DWC equipped with trays, the height of vapour column is $\sim 8.1 \mathrm{~m}$, which generates addi- 
Table 4 -Basic data and estimated pressure drop for packed beds, liquid distributors, and liquid collectors of the packed DWC shown in Fig. 4

\begin{tabular}{l|c|c|c|c|c|c|c|c}
\hline \multicolumn{1}{c|}{ Section } & & 1.1 & 1.2 & $2.1 \mathrm{a}$ & $2.1 \mathrm{~b}$ & $2.2 \mathrm{a}$ & $2.2 \mathrm{~b}$ & $2.2 \mathrm{c}$ \\
\hline \multicolumn{1}{c|}{ Packing } & & $350 \mathrm{MN}$ & $350 \mathrm{MN}$ & $350 \mathrm{MN}$ & $350 \mathrm{MN}$ & $350 \mathrm{MN}$ & $350 \mathrm{MN}$ & $350 \mathrm{MN}$ \\
\hline HETP & & 0.45 & 0.45 & 0.45 & 0.45 & 0.45 & 0.45 & 0.45 \\
$h$ & $\mathrm{~m}$ & 1.8 & 6.0 & 2.8 & 6.0 & 5.4 & 5.4 & 5.0 \\
$d$ & $\mathrm{~m}$ & 0.650 & 2.871 & 1.415 & 1.415 & 3.200 & 3.200 & 3.200 \\
$\Delta p$ & $\mathrm{mbar}$ & 3.11 & 0.25 & 2.36 & 4.56 & 0.71 & 0.84 & 0.99 \\
$N$ & - & 4 & 13 & 6 & 13 & 12 & 12 & 11 \\
$\Delta p / \Delta z$ & $\mathrm{mbar} \mathrm{m}^{-1}$ & 2.37 & 0.08 & 0.85 & 0.86 & 0.15 & 0.16 & 0.00 \\
\hline
\end{tabular}

\begin{tabular}{|c|c|c|c|c|c|c|c|c|}
\hline \multicolumn{9}{|c|}{ Internals } \\
\hline \multicolumn{9}{|c|}{ Distributors } \\
\hline Position & & 1.1 & 1.2 & $2.1 \mathrm{a}$ & $2.1 \mathrm{~b}$ & $2.2 \mathrm{a}$ & $2.2 \mathrm{~b}$ & $2.2 \mathrm{c}$ \\
\hline Type & & NT & NT & NT & NT & NT & NT & NT \\
\hline$\varphi_{\text {distr }}$ & - & 0.40 & 0.40 & 0.40 & 0.40 & 0.40 & 0.40 & 0.40 \\
\hline$F_{\mathrm{G}}$ & $\mathrm{Pa}^{0.5}$ & 1.56 & 0.10 & 1.32 & 1.32 & 0.49 & 0.55 & 0.57 \\
\hline$\Delta p$ & mbar & 0.06 & 0.00 & 0.04 & 0.04 & 0.01 & 0.01 & 0.01 \\
\hline \multicolumn{9}{|c|}{ Collectors } \\
\hline Position & & 1.1 & 1.2 & $2.1 \mathrm{a}$ & $2.1 \mathrm{~b}$ & $2.2 \mathrm{a}$ & $2.2 \mathrm{~b}$ & \\
\hline$u_{\mathrm{Le}}$ & $\mathrm{m}^{3} \mathrm{~m}^{-2} \mathrm{~h}^{-1}$ & 21.2 & 25.2 & 21.6 & 17.8 & 27.6 & 28.4 & \\
\hline Type & - & $\mathrm{CT}$ & $\mathrm{CC}$ & $\mathrm{CC}$ & $\mathrm{CT}$ & $\mathrm{CC}$ & $\mathrm{CC}$ & \\
\hline$\varphi_{\text {cc/ct }}$ & - & 0.25 & 0.250 & 0.100 & 0.112 & 0.25 & 0.25 & \\
\hline$F_{\mathrm{G}}$ & $\mathrm{Pa}^{0.5}$ & 1.34 & 0.37 & 1.32 & 1.18 & 0.57 & 0.59 & \\
\hline$\Delta p$ & mbar & 0.49 & 0.03 & 2.95 & 2.14 & 0.07 & 0.08 & \\
\hline \multicolumn{9}{|c|}{ Pressure drop equalization } \\
\hline Sections & & & \multicolumn{2}{|c|}{$1.1+1.2$} & \multicolumn{2}{|c|}{2.1} & & \\
\hline Packing & $\Delta p$ & mbar & \multicolumn{2}{|c|}{3.36} & \multicolumn{2}{|c|}{6.92} & & \\
\hline Internals & $\Delta p$ & mbar & \multicolumn{2}{|c|}{0.58} & \multicolumn{2}{|c|}{5.18} & & \\
\hline Vapour column & $\Delta p$ & mbar & \multicolumn{2}{|c|}{8.20} & \multicolumn{2}{|c|}{-} & & \\
\hline Total & $\Delta p$ & mbar & \multicolumn{2}{|c|}{12.14} & \multicolumn{2}{|c|}{12.18} & & \\
\hline
\end{tabular}

tional pressure drop of $\sim 11.6$ mbar, and makes the pressure drop on prefractionator side containing less trays to be somewhat lower than that on the main column side (141.6 mbar vs. 148.0 mbar). Such a small difference could be compensated by installing two additional trays or by increasing condenser pressure accordingly on prefractionator side.

In the case of TCDS configuration, the pressure drop of vapour transport line needs to be accounted for in addition to pressure drop of packings with ancillary equipment or trays in deethanizer column. Namely, in TCDS configuration, the $(\mathrm{C} 3+\mathrm{C} 4)$ column includes reboiler, and the required amount of vapour drawn-off in feed section of this column is transported to the bottom of $\mathrm{C} 2$ column via a pipe system consisting of horizontal and vertical straight sections including at least two smooth bends. The relative length and orientation of straight pieces of pipe as well as the number of bends will depend on spatial layout of two columns.

For the purpose of this design exercise, the bottoms of two columns are arranged to be at the same level, with shells in parallel at a distance of $5 \mathrm{~m}$. As illustrated schematically in Fig. 6, the exit of vapour, which is located in the feed stage area of $(\mathrm{C} 3+\mathrm{C} 4)$ column, is at a higher elevation than the top of the deethanizer column, to the extent depending on chosen internals.

In TCDS arrangement, the static pressure of the vapour column appears beneficial, compensating to a certain extent for the pressure drop of the transport line. This is more pronounced in the case of 


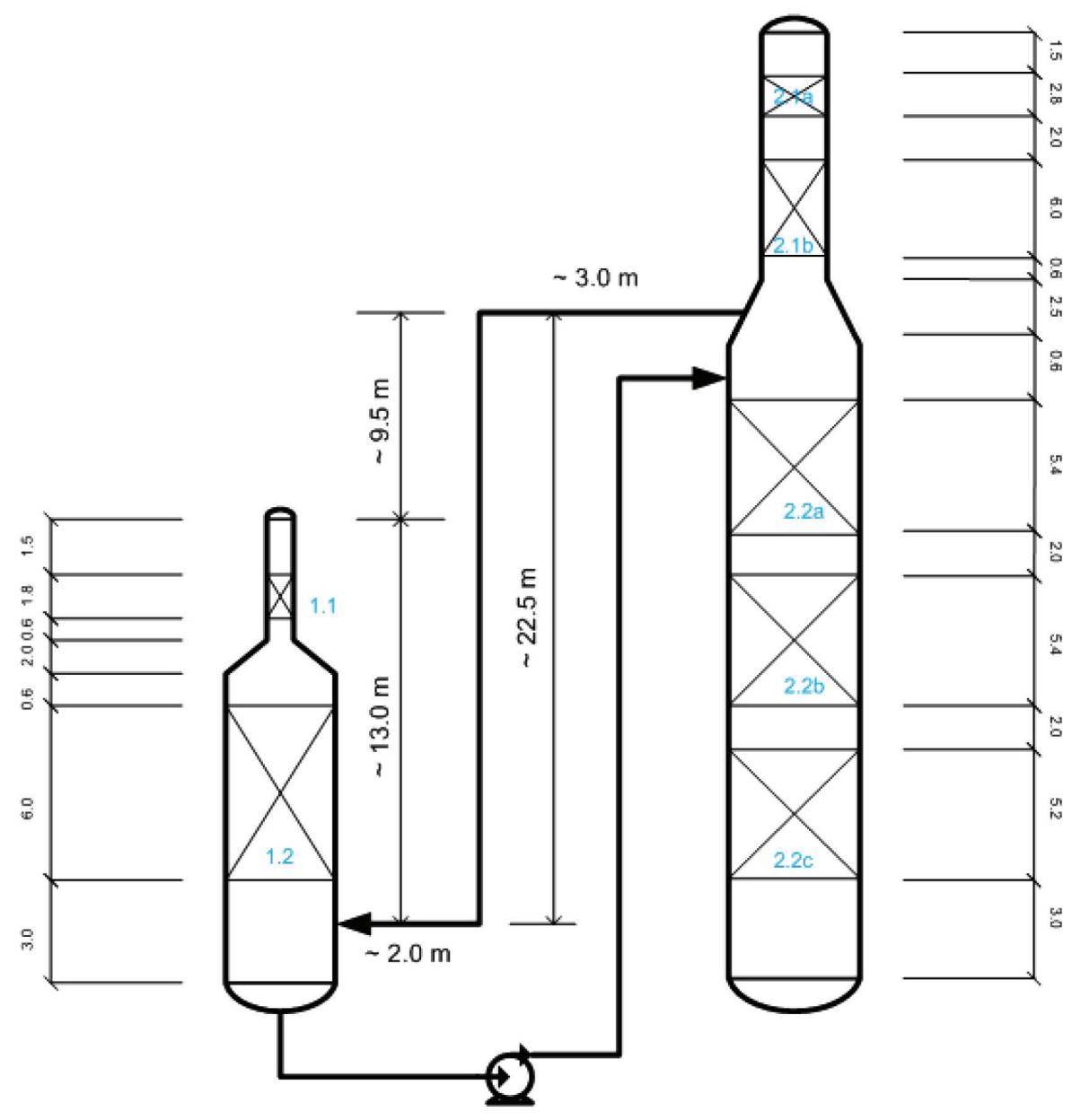

Fig. $6-C 2$ and $(C 3+C 4)$ columns positioning in TCDS arrangement indicating all relevant heights for pressure drop estimation in packed columns case

packed columns, because the difference in height between the vapour exit from $(\mathrm{C} 3+\mathrm{C} 4)$ column and the top of the deethanizer column is somewhat larger than is the case with tray columns. This is accounted for properly and used to fix the pressure of the top of deethanizer column.

The total length of the vapour transfer line is larger in the case of TCDS configuration utilising tray columns, i.e., 31.8 vs. $27.5 \mathrm{~m}$. This means a somewhat larger frictional pressure drop in the case of tray columns (for a transport line with internal diameter of $0.2 \mathrm{~m}$ it is $34.8 \mathrm{mbar}$, while that for packed columns it is $30.5 \mathrm{mbar})$. On the other hand, the difference in elevations of the top of deethanizer column and the position of the vapor exit in feed section of $(\mathrm{C} 3+\mathrm{C} 4)$ column is $\sim 5.6 \mathrm{~m}$ in the case of tray columns, and $\sim 7.5 \mathrm{~m}$ in the case of packed columns, making static pressure of the vapour column somewhat more pronounced in the case of packed columns $(\sim 14.1$ mbar vs. $\sim 10.5$ mbar $)$. In conjunction with pressure drop of deethanizer column, which is much smaller for packed column ( 4 mbar) than for trayed column ( $\sim 151$ mbar), this results in deethanizer top pressure of $\sim 8.29$ bar for packed columns and $\sim 8.22$ bar for trayed columns.

All estimated values may vary somewhat, but as mentioned earlier, in the present cases, designers are in a comfortable situation, because the possibility of adjusting condenser pressure provides a perfect means for ensuring the proper vapour split and smooth operation of both the TCDS and DWC configurations ${ }^{17}$. Additional safety in this respect could be ensured by installing flaps in the vapour lines connecting the column shell and condenser. These, provided with adequate control loops, would allow balancing (fine-tuning) of the pressure drop, if it appears necessary ${ }^{18}$.

For precautionary reasons, it is expected that an additional safety margin on the efficiency side will be implemented in the first DWC designs for this purpose. This would further increase the height of these columns, and could make them less attractive compared to conventional columns as employed in TCDS configuration. Note that, for the original floating facility related production capacity (10 times lower feed rate), the diameter of the packed 
DWC would be reduced to $0.25 \mathrm{~m}$ at the top, and $1.1 \mathrm{~m}$ for the main body. Trays are not an option in this case, and such a slender column (height to diameter ratio above 30 ) would resemble a mast towering very high above the main deck, and would be difficult to support appropriately. The amplitude of the swinging/swaying of the top of the column would be excessively large, and this could even worsen with additional wind effect.

However, DWC in this case is only moderately higher than the $(\mathrm{C} 3+\mathrm{C} 4)$ column in TCDS. In other words, the $(\mathrm{C} 3+\mathrm{C} 4)$ column could also be considered as a slender column requiring additional measures to ensure proper support, which is more difficult to arrange on a floating facility than in an on-land plant. For on-land plants, trayed columns are the preferred choice, and here also the difference in shell height of a DWC and the $(\mathrm{C} 3+\mathrm{C} 4)$ column in TCDS configuration is not that large that it could be considered prohibitive. Even if a safety margin of 10 to $15 \%$ is adopted for DWC to cover the potential loss of efficiency of trays installed in the partitioned section, this would only slightly increase the shell height of the DWC. Therefore, both TCDS and DWC configurations equipped with trays are potential candidates for on-land NGL fractionation plants. The latter is taller but requires less plot area, and the decision which option to take may depend on the situation on site.

In any case, though not considered appropriate for high-pressure distillations, packed columns are the preferred candidates for floating plants. Here, the need for minimization of the plot area and weight may favour the DWC, but a lot of daring will be needed on the design and installation side to find affordable means to ensure mechanical stability and operational functionality of such a slender column. Concerns remain regarding the absence of any information in the public domain on the level of separation efficiency achievable with structured packings in offshore applications. Encouragingly, a quick survey of patent literature has indicated that a major player in the field of equipment for distillation, i.e., Sulzer Chemtech, is engaged in the development and potential implementation of a new type of tray that "is in particular usable for offshore applications, such as for a fractionation column on a FLNG or FPSO vessel"14.

\section{Concluding remarks}

Heat coupling could bring significant savings in energy requirement on heating side and an equivalent reduction in related carbon dioxide emissions if implemented in thermodynamically unfriendly environment of a NGL fractionation plant.
For a simple NGL fractionation plant employing a conventional three-column direct sequence for separation of methane, ethane, $(\mathrm{C} 3+\mathrm{C} 4)$, and $\mathrm{C} 5+$ components, this could be achieved either by external heat coupling utilising a conventional demethanizer and heat coupled deethanizer and $(\mathrm{C} 3+\mathrm{C} 4)$ columns (TCDS configuration) or by internal heat coupling utilising a conventional demethanizer and a three-product dividing-wall column (DWC configuration).

Utilising adopted design and construction methodology, it is demonstrated that, in both cases, i.e., trayed or packed columns, the vapour split can be arranged accordingly by design. Importantly, both TCDS and DWC configurations allow the cooling duty of condensers to be used to adjust and maintain the desired vapour split during operation.

Potential column construction related barriers have been addressed and discussed. In on-land applications, tray columns are the preferred choice, while for floating facilities, packed columns, less sensitive to motion-induced performance-deteriorating effects, should be considered. Nevertheless, developments toward enabling efficient application of trays in offshore high-pressure distillation operations in the near future are taking place.

Additional measures are required to ensure mechanical stability and operational functionality of both $(\mathrm{C} 3+\mathrm{C} 4)$ column from TCDS configuration and a DWC for floating facilities, because these columns can have prohibitively large height to diameter ratios. Although it requires a larger plot area, an important advantage of TCDS configuration is the use of proven conventional column designs, and a lower shell height brings advantages on both mechanical and processing sides.

Significant progress has been made, but it appears that further physical implementation related improvements are deemed necessary to lower the barriers for installing thermal coupling technology in floating natural gas liquefaction plants.

\section{List of symbols}

$d \quad-$ diameter of a section in a DWC, $\mathrm{m}$

$d_{\mathrm{r}} \quad-$ diameter of rectification section, $\mathrm{m}$

$d_{\mathrm{s}} \quad-$ diameter of stripping section, $\mathrm{m}$

$F_{\mathrm{G}} \quad-$ vapour load or F-factor, $\mathrm{Pa}^{0.5}$

$h_{\text {bed }} \quad-$ height of a packed bed, $\mathrm{m}$

$h_{\mathrm{tt}} \quad-$ tangent to tangent height of a column shell, $\mathrm{m}$

$N \quad$ - number of equilibrium stages, -

$N_{\text {act }} \quad-$ actual number of trays, -

$N_{\mathrm{r}} \quad-$ number of equilibrium stages in rectification section, - 


$\begin{array}{ll}N_{\mathrm{s}} & -\begin{array}{l}\text { number of equilibrium stages in stripping } \\ \end{array} \\ & \text { section, }- \\ p_{\text {top }} & - \text { pressure at the top of the column, bar } \\ \Delta p & - \text { pressure drop, mbar } \\ \varphi_{\text {distr }} \quad- & \text { free area fraction of a liquid distributor, }- \\ \varphi_{\mathrm{cc}} & - \text { free area fraction of a chevron (vane) type } \\ & \text { liquid collector, }- \\ \varphi_{\mathrm{ct}} & - \text { free area fraction of a chimney tray type liq- } \\ & \text { uid collector, }-\end{array}$

\section{Abbreviations}

$\begin{array}{ll}\text { Bayer TS } & - \text { Bayer Technical Services } \\ \text { CC } & - \text { chevron or vane type liquid collector } \\ \text { CT } & - \text { chimney tray type liquid collector } \\ \text { C1 } & - \text { demethanizer column \& methane } \\ \text { C2 } & - \text { deethanizer column \& ethane } \\ \text { C3+C4 } & - \text { propane-butane recovery column \& } \\ & \text { propane }+ \text { butane } \\ \text { C5+ } & - \text { pentane and heavier components } \\ \text { DWC } & - \text { dividing wall column } \\ \text { FLNG } & - \text { Floating Liquefied Natural Gas } \\ \text { FPSO } & - \text { Floating Production Storage Offloading } \\ \text { FRI } & - \text { Fractionation Research Inc. } \\ \text { HETP } & - \text { height equivalent to a theoretical plate or } \\ & \quad \text { equilibrium stage } \\ \text { MC } & - \text { main column } \\ \text { NGL } & - \text { natural gas liquids } \\ \text { NT } & - \text { narrow trough liquid distributor } \\ \text { TCDS } & - \text { thermally coupled direct sequence }\end{array}$

\section{References}

1. Halvorsen, I. J., Dejanović, I., Maråk, K.-A., Olujić, Ž., Skogestad, $S$., Dividing-wall column for fractionation of natural gas liquids in floating liquefied natural gas plants, Chem. Eng. Technol. 39 (2016) 2348. doi: https://doi.org/10.1002/ceat.201500698

2. Halvorsen, I. J., Dejanović, I., Olujić, Ž., Skogestad, S., Dividing wall columns for natural gas liquefaction plants, Chem. Eng. Transactions 69 (2018) 829.

3. Manley, D. B., Thermodynamically efficient distillation: NGL fractionation, Latin American Applied Research 28 (1998) 4, 212.

4. Long, N. V. D, Lee, M. Y., Improvement of natural gas liquid recovery energy efficiency through thermally coupled columns, Asia-Pac. J. of Chem. Eng. 7 (2012) (Suppl. 1): S71.
5. Kaibel, B., Dividing-Wall Columns. in Gorak, A. and Olujić, Ž. (Eds.) Distillation: Equipment and Processes, Academic Press/Elsevier, 2014, pp. 183. doi: https://doi.org/10.1016/B978-0-12-386878-7.00005-X

6. Roza, M., Zuber, L., Most recent development on design and operation of distillation and absorption columns under moving conditions, Proceedings of Distillation Conference, AIChE Spring National Meeting, March 30 - April, 3, 2003, New Orleans, LA, USA, pp. 577-588.

7. Cullinane, J. T., Yeh, N., Grave, E., Effects of Tower Motion on Packing Efficiency, Brazil Offshore, 14-17 June 2011, SPE 143766. ISBN 978-1-61399-123-7.

8. Spiegel, L., Duss, M., Structured Packings, in Gorak, A. and Olujić, Ž. (Eds.) Distillation: Equipment and Processes, Academic Press/Elsevier, 2014, pp. 145. doi: https://doi.org/10.1016/B978-0-12-386878-7.00004-8

9. Olujić, Ž., Vacuum and High Pressure Distillation, in Gorak, A. and Olujić, Ž. (Eds.) Distillation: Equipment and Processes, Academic Press/Elsevier, 2014, pp. 295. doi: https://doi.org/10.1016/B978-0-12-386878-7.00009-7

10. Dejanović, I., Matijašević, Lj., Jansen, H., Olujić, Ž., Designing a packed dividing wall column for an aromatics processing plant, Ind. Eng. Chem. Res. 50 (2011) 5680. doi: https://doi.org/10.1021/ie1020206

11. Olujić, Ž., Dejanović, I., Kaibel, B., Jansen, H., Dimensioning multipartition dividing wall columns, Chem. Eng. Technol. 35 (2012) 1392. doi: https://doi.org/10.1002/ceat.201100709

12. Dejanović, I., Halvorsen, I. J., Skogestad, S., Jansen, H., Olujić, Ž., Hydraulic design, technical challenges and comparison of alternative configurations of a four-product dividing wall column, Chem. Eng. Process. 84 (2014) 71. doi: https://doi.org/10.1016/j.cep.2014.03.009

13. Olujić, Ž., Rietfort, T., Jansen, H., Zich, E., Frey, G., Ruffert, G., Zielke, T., Experimental characterization and modelling of high performance structured packings, Ind. Eng. Chem. Res. 51 (2012) 4414. doi: https://doi.org/10.1021/ie202585t

14. Olujić, Ž., Jansen, H., Rietfort, T., Zich, E., Performance characteristics of an intermediate area high performance structured packing, Chem. Eng. Res. Des. 99 (2015) 14. doi: https://doi.org/10.1016/j.cherd.2015.03.004

15. Fractionation Research Inc., Test of Montz Cross-Flow Tray Type KSG, Technical Report (TR 81) 1978.

16. Resetarits, M., Distillation Trays, in Gorak, A. and Olujić, Ž. (Eds.) Distillation: Equipment and Processes, Academic Press/Elsevier, 2014, pp 35-84. doi: https://doi.org/10.1016/B978-0-12-386878-7.00002-4

17. Luyben, W. L., Vapor split manipulation in extractive divided wall distillation columns, Chem. Eng. Process. 128 (2018) 132. doi: https://doi.org/10.1016/j.cep.2018.02.022

18. Staak, D., Grŭtzner, T., Process integration by application of an extracting dividing wall column: An industrial case study, Chem. Eng. Res. Des. 123 (2017) 120. doi: https://doi.org/10.1016/j.cherd.2017.04.003

19. Shields, S., Krishnamoorthy, S., Duss, M. (Sulzer Chemtech AG) US Pat. Appl. US 2017/0348609 A1, 7 Dec 2017. 